\title{
Modulated and continuous-wave operations of low-power thulium (Tm:YAP) laser in tissue welding
}

Temel Bilici

Haşim Özgür Tabakoğlu

Nermin Topaloğlu

Boğaziçi University

Biomedical Engineering Institute

Biophotonics Laboratory

Istanbul, 34342 Turkey

Hamit Kalaycıoğlu

Koç University

Department of Physics

Laser Research Laboratory

Istanbul, 34450 Turkey

\section{Adnan Kurt}

Teknofil Ltd.

Sti. Zekeriyaköy

Istanbul, 34450 Turkey

\section{Alphan Sennaroglu \\ Koç University \\ Department of Physics \\ Laser Research Laboratory \\ Istanbul, 34450 Turkey}

\author{
Murat Gülsoy \\ Boğaziçi University \\ Biomedical Engineering Institute \\ Biophotonics Laboratory \\ Istanbul, 34342 Turkey
}

\begin{abstract}
Our aim is to explore the welding capabilities of a thulium (Tm:YAP) laser in modulated and continuous-wave (CW) modes of operation. The Tm:YAP laser system developed for this study includes a Tm:YAP laser resonator, diode laser driver, water chiller, modulation controller unit, and acquisition/control software. Full-thickness incisions on Wistar rat skin were welded by the Tm:YAP laser system at $100 \mathrm{~mW}$ and $5 \mathrm{~s}$ in both modulated and CW modes of operation $\left(34.66 \mathrm{~W} / \mathrm{cm}^{2}\right)$. The skin samples were examined during a 21-day healing period by histology and tensile tests. The results were compared with the samples closed by conventional suture technique. For the laser groups, immediate closure at the surface layers of the incisions was observed. Full closures were observed for both modulated and CW modes of operation at day 4. The tensile forces for both modulated and CW modes of operation were found to be significantly higher than the values found by conventional suture technique. The 1980-nm Tm:YAP laser system operating in both modulated and CW modes maximizes the therapeutic effect while minimizing undesired side effects of laser tissue welding. Hence, it is a potentially important alternative tool to the conventional suturing technique. (๑) 2010 Society of Photo-Optical Instrumentation Engineers. [DOI: 10.1117/1.3431108]
\end{abstract}

Keywords: laser tissue welding; 1980 nm; thulium; Wistar rat skin; histology; tensile strength.

Paper 09540RR received Dec. 3, 2009; revised manuscript received Mar. 14, 2010 ; accepted for publication Mar. 30, 2010; published online May 26, 2010.

\section{Introduction}

Laser tissue welding is an alternative method to bond tissues by using laser energy. In the mechanism of laser tissue welding, the photonic energy is converted to thermal energy. Therefore, the choice of laser wavelength for tissue welding is mostly based on the absorption of the laser energy by tissue chromophores. The first use of laser tissue welding was reported in small blood vessels with an Nd:YAG laser. ${ }^{1}$ Laser tissue welding has been used for several tissue types including nerve, ${ }^{2}$ intestine, ${ }^{3}$ cornea, ${ }^{4}$ arteries, ${ }^{5}$ and skin, ${ }^{6}$ and by using a variety of lasers such as diode, ${ }^{7} \mathrm{Nd}: \mathrm{YAG}^{8}$ and $\mathrm{CO}_{2}{ }^{9}$ lasers.

Laser tissue welding provides a watertight closure with a reduction in foreign-body reaction, suture and needle trauma, bleeding, surgical times, and skill requirements. The suture technique for closure of wounds by dermatologic surgeons is relatively time-consuming to perform for a long wound and provides poor cosmetics. Sutureless methods for closure of surgical incisions such as staples, strips, sealants, and glues are difficult to apply, and they may carry a risk of foreign-

Address all correspondence to Murat Gulsoy, Associate Professor, Bogazici University, Institute of Biomedical Engineering, Bebek, Istanbul, 34342 Turkey. Tel: 90-216-516-3460; Fax: 90-216-516-3479; E-mail: gulsoy@boun.edu.tr body reaction. ${ }^{10}$ Since the suture material inside the reparative tissue contributes to a characteristic foreign-body reaction, it accumulates macrophages in the healing granulation tissue. ${ }^{11}$ Laser tissue welding prevents foreign bodies or toxic elements from entering the wounded tissue and improves cosmetic results with no need to use needle and stitch removal. Another important characteristic of laser tissue welding is operation time. Operations $25 \%$ faster have been achieved with laser application than with the corresponding suturing procedure. ${ }^{12}$ In another study, the laser tissue welding operation was found to be four times faster than the conventional suture technique. $^{13}$

The interest in lasers emitting in the $2-\mu \mathrm{m}$ region has been increasing continuously for tissue welding applications. Laser welding of gallbladder incisions with a mid-infrared 2.15- $\mu \mathrm{m}$ thulmium-holmium-chromium (THC):YAG laser (1.5 W) has been offered as a useful technique for future developments of $2-\mu \mathrm{m}$ lasers. ${ }^{14}$ The tissue absorption characteristics by (TH$\mathrm{C})$ :YAG laser in pulsed mode of operation permitted tissue welding with limited collateral thermal damage in percutaneous endoscopic biliary surgery. ${ }^{15}$ On the other hand, a thulium

1083-3668/2010/15(3)/038001/9/\$25.00 @ 2010 SPIE 


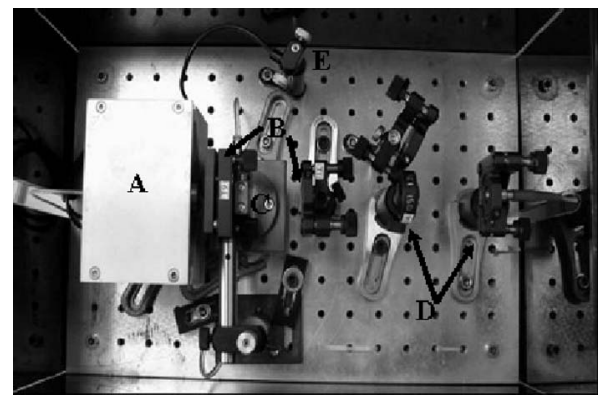

Fig. 1 Tm:YAP laser setup (A: pump diode laser with telescope and chiller system; B: mirror and output coupler; C: Tm:YAP crystal with chiller system; D: fiber coupling; E: pilot beam).

fiber laser at $1873 \mathrm{~nm}$ with about $600 \mathrm{~mW}$ was used to produce full-thickness, watertight tissue closure during microsurgical laser welding of urinary tissues. ${ }^{16}$ In another study, tissue welding by a continuous-wave (CW) Ho:YAG laser was compared to laser soldering by $808-\mathrm{nm}$ diode laser, and both techniques revealed good bursting pressures of anastomoses. ${ }^{17}$ A low-power $1.95-\mu \mathrm{m}$ diode laser was chosen to weld small vessels to result in uniform deposition of energy across the thickness of the weld. ${ }^{18}$

At the $2-\mu \mathrm{m}$ region, laser energy can be delivered via optical fibers, and it can be absorbed very well by water molecules, which is a main constituent of biological tissue. The absorption coefficient at $1980 \mathrm{~nm}\left(\mu_{a}=92.03 \mathrm{~cm}^{-1}\right)$ was reported as 760 times better than one of the most popular medical lasers at $1064 \mathrm{~nm}\left(\mu_{a}=0.12 \mathrm{~cm}^{-1}\right) .{ }^{19}$ The Tm:YAP laser at $1.98 \mu \mathrm{m}$ has a stronger absorption coefficient in liquid water than Tm:YAG and Ho:YAG lasers around $2 \mu \mathrm{m} .{ }^{20}$ The lasers near $3 \mu \mathrm{m}$ have the highest absorption in tissue because they overlap with the fundamental $0-\mathrm{H}$ vibrational stretch mode of water. However, silica fibers are not transparent at wavelengths longer than $2 \mu \mathrm{m}$. The Tm:YAP laser at $1.98 \mu \mathrm{m}$ can be coupled to the conventional silica fibers as opposed to longer-wavelength lasers like $\mathrm{CO}_{2}$ lasers emitting at $10.6 \mu \mathrm{m} .{ }^{21}$ As an additional advantage, lasers with a wavelength longer than 1.4 microns are in the "eyesafe" band. Hence, laser radiation around $2 \mu \mathrm{m}$ does not damage the retina because it is absorbed by water in the human eye before reaching the retina, ${ }^{22}$ and this greatly reduces health risks during the operation of the laser.

In this study, our objective was to develop a Tm:YAP laser system for tissue welding applications. The aim was to explore the capability of that system under different modes of operation for making strong welds. The modulated and CW modes of operation were tested in vivo, and results were analyzed through histological examinations and tensile strength tests.

\section{Methods}

\subsection{Tm:YAP Laser System}

The Tm:YAP laser system developed in this study includes a Tm:YAP laser setup, a diode laser driver, a water chiller for the laser setup, a modulation controller unit, and an acquisition/controller software. In the Tm:YAP laser setup (Fig. 1), the Tm:YAP crystal (Tm concentration $=1.5 \%$,
$5 \mathrm{~mm}$ diameter $=5 \mathrm{~mm}$, length $=4 \mathrm{~mm}$ ) was used as the laser medium. ${ }^{23}$ It was normal cut, and both faces had antireflection coatings at $1980 \mathrm{~nm}$. The Tm:YAP resonator was endpumped with a fiber-coupled diode array operating at a wavelength of $797 \mathrm{~nm}$. An imaging telescope was used to focus the pump beam into the crystal. The resonator consisted of a flat input mirror and a curved output coupler with a radius of $10 \mathrm{~cm}$. The length of the resonator was $7.5 \mathrm{~cm}$. An output coupler with $6 \%$ transmission was used. The Tm:YAP crystal was positioned near the dichroic input mirror. The crystal was wrapped in indium foil and held between copper holders that were cooled by circulating water to $20^{\circ} \mathrm{C}$. Laser radiation was delivered by means of a $200-\mu \mathrm{m}$ multimode fiber optic cable.

In the Tm:YAP laser system, the modulation microcontroller unit provides the modulation for the Tm:YAP laser output. The microcontroller unit can modulate the laser up to a frequency of $50 \mathrm{~Hz}$. The user interface on the computer sets the power and the duration of the laser emission with on cycles, off cycles, and number of cycles. By setting the diode current, the Tm:YAP laser system emits radiation up to $1.2 \mathrm{~W}$ at $1980 \mathrm{~nm}$.

\subsection{Animal Preparation}

The experiments were conducted under a protocol approved by the Institutional Animal Research and Care Ethics Committee at Bogazici University. A total of 52 healthy male Wistar rats, 5 to 6 months old, weighing 240 to $250 \mathrm{~g}$, were randomly selected from the Psychobiology Laboratory of Bogazici University for in vivo experiments. Rats were housed in plastic cages and maintained on a 12-h-light/12-h-dark cycle in a temperature-controlled vivarium $\left(22 \pm 2{ }^{\circ} \mathrm{C}\right)$. Food and water were available ad libitum. Rats were anesthetized with ketamine (10\% ketamidor, RichterPharma, AG, Wels, Austria) by intraperitoneal injection $(1.65 \mathrm{ml} / \mathrm{kg})$. Hair at the site of application of each subject was shaved. Three pairs of 10-mm-long, full-thickness incisions bilateral and parallel to the spinal cord were created on each animal using a no. 11 scalpel. ${ }^{24}$ The length of the incisions was sustained via a calibrated micrometer. For good apposition, incisions were created such that there was no opening of incision after mechanical contact. Any blood exposed on the incision surface was cleaned to prevent blood from interfering with the laser welding process.

\subsection{Welding by Tm:YAP Laser System}

The entire laser application procedure was conducted by one operator. Laser protective glasses were used when the laser was active. Power, duration, and mode of operation (modulated and $\mathrm{CW}$ ) parameters were set by the user through the user interface on the PC. Laser output power was checked with a power meter (Newport 1918-C, Irvine, California) before each application. The laser application was repeated six times along the incision at a distance of $2 \mathrm{~mm}$ above each incision, which was determined for optimal noncontact application to prevent laser divergence and fiber damage. The laser spot diameter was measured from $2 \mathrm{~mm}$ as $0.6 \mathrm{~mm}$ by using the knife-edge technique. 


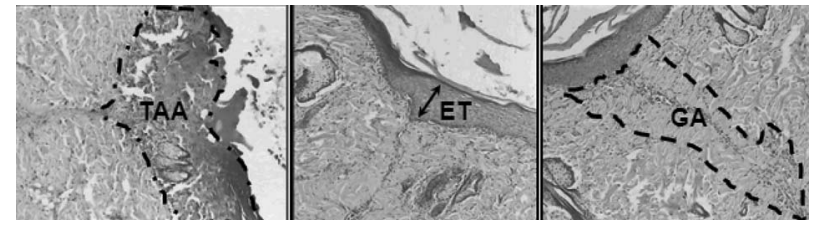

Fig. 2 Measurement of thermally affected area (TAA), epidermal thickness (ET), and granulation area (GA) on histology images for quantitative analyses. TAA shows the thermal changes after the laser application. ET is the maximum thickness measured on the epidermis at the laser application site. GAA is the measured area with new fibroblasts, inflammatory cells, and capillaries along the welded part.

\subsection{Histology Analysis}

Laser-welded tissue samples underwent histological analysis to determine the tissue welding success. The wounds on the rats were examined during the recovery period. Presence of wound reopening, infection, and scar and hair formation were checked on a daily basis. The rats were sacrificed by cervical dislocation on postoperative days of $1,4,7,14$, and 21 for histological analysis study on cross sections of each welded sample. The full incision site was excised with a scalpel. The samples were fixed in formalin, sectioned as longitudinal and cross sections, and stained with hematoxylin-eosin. Skin samples were examined under a light microscope (Eclipse 80i, Nikon Co., Tokyo, Japan), and images were taken with a CCD camera (DS-Fi1, Nikon Co.). Measurements were performed using Imaging software (NIS Elements-D, Nikon Co.).

For each dose group, a quantitative determination of closure index (CI), thermally affected area (TAA), epidermal thickness (ET), and granulation area (GA) was performed (Fig. 2). CI is the primary indicator for skin closure by welding. It is defined as the ratio of closed parts to the total incision $(\mathrm{CI}=$ closed length/total incision $)$. CI values range from zero to one. $\mathrm{CI}=0$ corresponds to no closure, and $\mathrm{CI}=1$ means full closure. TAA reveals the thermal changes of a laser-welded part. The thermal changes are identified under light microscope as color change and morphological degeneration due to the denaturation of cellular structures. ET shows the quality of healing, and it depends on the thermal effects and inflammations. GAA is the area where new fibroblasts, inflammatory cells, and capillaries are formed along the incisions.

\subsection{Tensile Strength Analysis}

Tensile strength measurements were performed at intervals over $1,4,7,14$, and 21 days after the operation for each sampled dose. For tensile-test examinations, incision sites were removed at about 5 -cm-long samples. Tensile tests were performed immediately within $10 \mathrm{~min}$ after the sample removal. Samples were locked between the test machine (LF Plus, Lloyd Instruments, Leicester, UK) jigs in such a way that grips (TG34, Lloyd Instruments) were as close as possible (about $3 \mathrm{~mm}$ ) and skin-sample slippage through the jigs was prevented. The test machine load cell capacity was $250 \mathrm{~N}$, and each sample was tested at $5 \mathrm{~mm} / \mathrm{min}$ crosshead velocity. Tension was applied until the repair failed, and the breaking force was recorded for each sample. The minimum load at which the welded sample failed was recorded by computer-controlled software (Nexygen Plus, Lloyd Instruments).

\subsection{Suture}

To compare the histology and tensile analysis of the samples welded by the Tm:YAP laser system with samples closed by conventional suture technique, a total of 120 incisions of 20 Wistar rats were closed by suture. A single suture USP-3/0 metric silk (Dogsan Tibbi Malzeme San. A. S., Trabzon, Turkey) was placed in the middle of each 1-cm-long incision. The distance between the needle entrances to the tissue was about $10 \mathrm{~mm}$.

\subsection{Data Analysis}

The data were analyzed by student's $t$-test (paired two-tail) assuming equal variance with a confidence interval of $95 \%$. A value of $p<0.05$ was considered statistically significant. Some data were expressed as average \pm standard deviation. For ethical reasons, the total of animals sacrificed was limited to a 52 Wistar rats, and each incision sample on each animal was assumed to be statistically independent.

\section{Results and Discussion}

\subsection{Dosimetry Study}

In this first part of the experimental study, several Tm:YAP laser parameters were tested to find the optimum dosimetry for tissue welding before sampling. The selected doses were applied to two Wistar rats, as each dose was sampled by 2 . In the modulated mode of operation, the cycle consisting of $200 \mathrm{~ms}$ on and $200 \mathrm{~ms}$ off of laser radiation was selected because it was observed to provide smaller thermally altered area and maximum penetration depth in another group of experiments. The healing period for this analysis was determined as 4 days. At day 4, macropictures of each incision were recorded, and the rats were sacrificed.

The applied laser parameters to each incision are tabulated in Fig. 3. The figure also includes macropictures of each incision to observe the effects of laser parameters just after the application (0-day) and 4 days later (4-day). The macropictures and also the histology pictures offer successful welding at $100-\mathrm{mW}, 5-\mathrm{s}$ modulated and CW dose of Tm:YAP laser. This result is very promising for efficient tissue welding at low powers of Tm:YAP laser at $100 \mathrm{~mW}$ in both modulated and $\mathrm{CW}$ modes of operation. However, the success should be proven by histology and tensile strength analysis at this dosimetry during the healing period until day 21 .

\subsection{Results of Histology Analysis}

The laser parameters determined by dosimetry study at modulated and $\mathrm{CW}$ operation modes were applied to the incisions on different rat samples. There were six incisions on each rat, incision numbers of 1, 2, and 3 were welded by Tm:YAP laser at $100 \mathrm{~mW}, 34.66 \mathrm{~W} / \mathrm{cm}^{2}$, CW during $5 \mathrm{~s}$ for each shot. Incisions numbered 4,5 , and 6 were welded by Tm:YAP laser at $100 \mathrm{~mW}, 34.66 \mathrm{~W} / \mathrm{cm}^{2}$, modulated $(200 \mathrm{~ms}$ on/200 ms off, for a total "on" duration of $5 \mathrm{~s}$ ) mode of operation. The rats were sacrificed at first (day 1), fourth (day 4), seventh (day 7), fourteenth (day 14), and twenty-first (day 21) recov- 


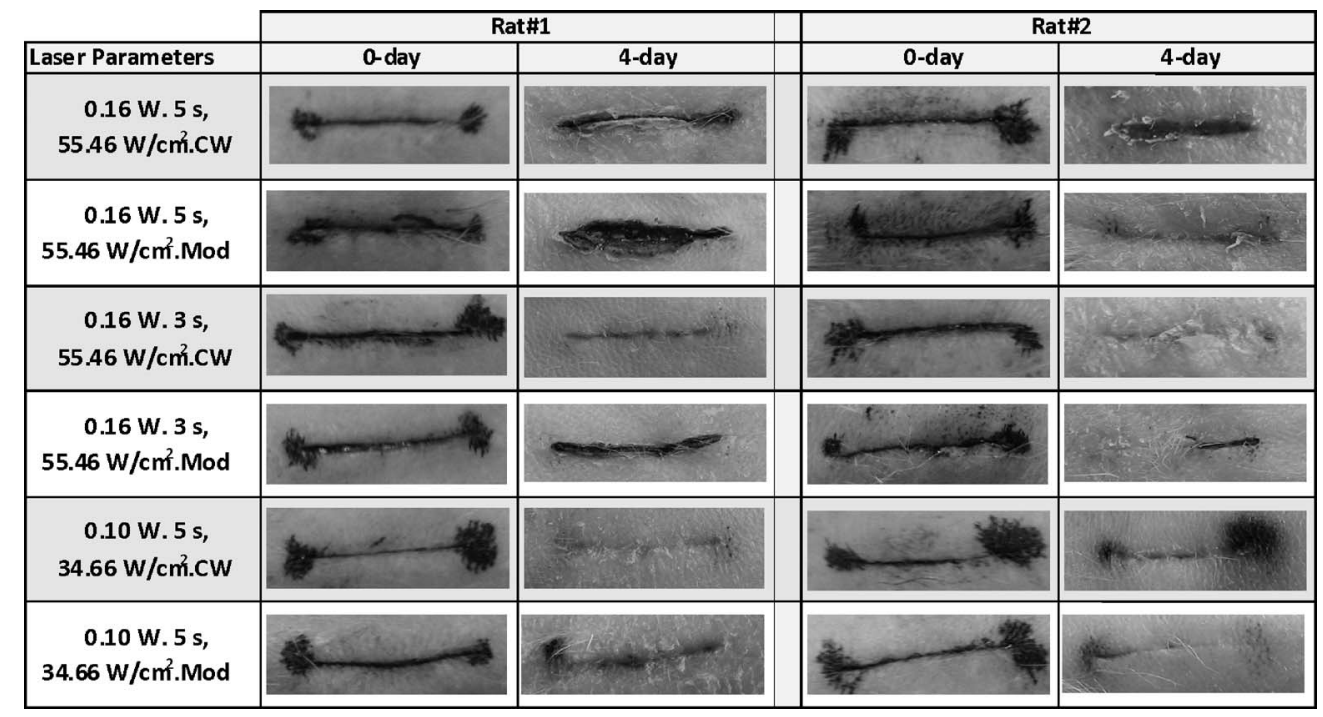

Fig. 3 Macropictures of each incision of the two rats and their applied laser parameters for dosimetry study. Successful welding at 100 mW, $5 \mathrm{~s}$ in both modulated and CW modes of Tm:YAP laser were obtained with maximum closure and minimum thermal side effects.

ery days after the laser welding operations. The quantitative histology analysis was performed with an optical microscope. A total of 60 incisions were sampled on 10 Wistar rats. Twenty slides of each incision were histologically imaged under the microscope.

The sufficient closure on the incisions was observed in the macroscopic pictures, and no side effects were observed during the healing period. Macroscopic examinations showed that welding had thinner and minimal scarring with quality healing. No inflammation was evident. During the healing period, no anomalies were observed in health conditions, dietary habits, or behaviors of rats.

The selected histology images of samples corresponding to the modulated and CW modes of operation of Tm:YAP laser during the healing period are given in Fig. 4. According to the histology images taken with the optical microscope, the incisions at day 1 were closed partially for both modulated and $\mathrm{CW}$ modes of operation. After day 4, full closure was obtained for both laser operations. Figure 4 also includes the histology images of samples closed by suture technique. In the suture group, closure was not observed for day 1 and day 4. The histological analysis parameters were analyzed for each slide of each incision $(n=180)$, and their average and standard deviation were calculated.

By day 1 , in the laser-welded incisions, the reepithelization process started. Welded wounds were closed at the epidermis, but some openings remained in dermis. After day 4, full closures were observed for both modes of operation $(\mathrm{CI}=1)$. At day 1 , the CI was higher for modulated mode (CI $=0.12 \pm 0.05$ for $\mathrm{CW}$ and $\mathrm{CI}=0.24 \pm 0.10$ for modulated, $p$ $<0.01)$. In the suture group, the CI value was found to be 0 for day $1, \mathrm{CI}=0.12 \pm 0.09$ for day 4 , and $\mathrm{CI}=1$ after day 4 . TAA values were observed only at day 1 , and no thermally altered area was observed after day 1. TAA was found lower for the modulated mode of operation. However, TAA values were not significantly different for modulated and $\mathrm{CW}$ modes of operation at day $1\left(\mathrm{TAA}=0.14 \pm 0.05 \mathrm{~mm}^{2}\right.$ for $\mathrm{CW}$ and $\mathrm{TAA}=0.12 \pm 0.04 \mathrm{~mm}^{2}$ for modulated at day $1, p=0.74$ ).
Carbonization was not observed in any of the welded incisions. At day 4 and day 7, reepithelization was completed, and wounds were fully closed. A layer of granulation tissue around full thickness through the skin was observed with deposition of fibroblast cells and collagen formation. By day 14 , tissue volume was partially replaced with granulation tissue as the epidermal hyperplasia began to decrease. By day 21 , for the sutured wounds, a full-thickness layer of granulation tissue was observed. The epidermal hyperplasia decreased, and the epidermal thickness reached normal width. In both groups, the granulation zone was broad near the epidermis and disappeared in the mid-dermis as a result of the decreased thermal effect on the mid-dermis.

ET was observed after day 4 on the incisions (Fig. 5). ET was found less ( $p<0.01$ for day 4 , day 7 , and day 14) in the modulated mode of operation. ET was decreasing during the healing period and recovering its normal thickness. ET values in the suture samples were found significantly higher at day 7 , day 14, and day 21 than the samples welded by modulated and CW modes of operation of the Tm:YAP laser. GA values are given in Fig. 6. GA was found as $0.04 \pm 0.02 \mathrm{~mm}^{2}$ for the modulated mode, whereas GA was found to be 0 for $\mathrm{CW}$ at day 1 . At day 4 , day 7 , and day 21 , there was no statistically significant difference between modulated and $\mathrm{CW}$ modes of operation. At day 14, the GA value was found higher for the samples exposed to the modulated mode of operation (GA $=0.39 \pm 0.03 \mathrm{~mm}^{2}$ for $\mathrm{CW}$ and $\mathrm{GA}=0.48 \pm 0.02 \mathrm{~mm}^{2}$ for modulated, $p<0.01)$. In the suture group, GA was observed at day 7, day 14, and day 21. GA values in the suture group were found less than both modulated and $\mathrm{CW}$ modes of operation $(p<0.01)$

\subsection{Results of Tensile Strength Analysis}

In total, 60 incisions were sampled on 20 Wistar rats; incisions of 10 rats exposed to the $\mathrm{CW}$ mode of operation $(100 \mathrm{~mW}, 5 \mathrm{~s})$ and incisions of the other 10 rats exposed to the modulated mode of operation $(100 \mathrm{~mW}, 200 \mathrm{~ms}$ 


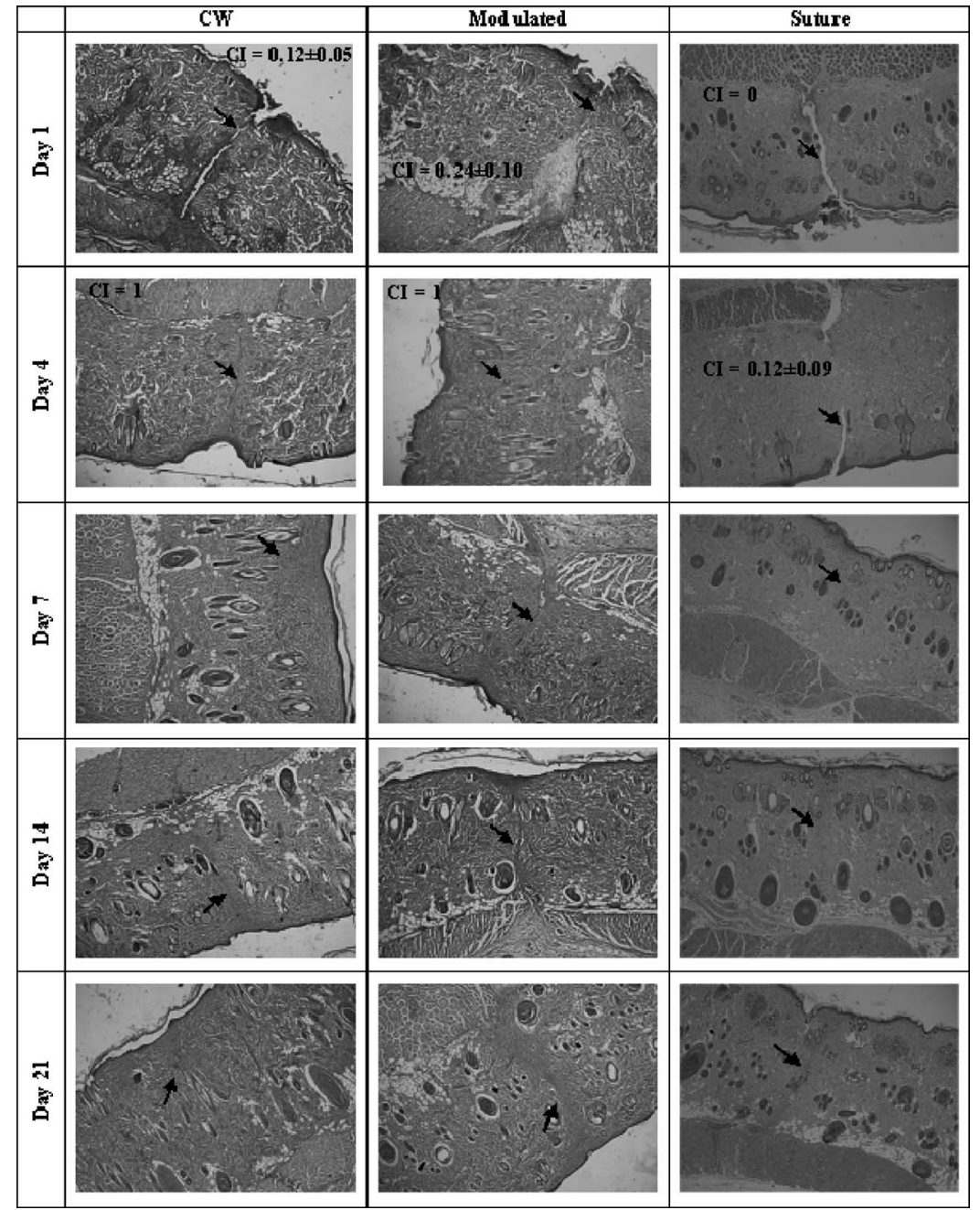

Fig. 4 Birefringent histology images of samples exposed to CW and modulated modes of the Tm:YAP laser. Arrows show the incisions, and CI values were embedded into the pictures. $\mathrm{Cl}$ was found to be 1 at day 4 for the incision samples welded by $\mathrm{CW}$ and modulated modes of operation of the Tm:YAP laser. $\mathrm{Cl}=1$ for all sampled groups after day 4 . Immediate events such as homeostasis and inflammation (day 1 and day 4), proliferation stage including granulation tissue formation, reepithelialization, fibroplasias, wound contraction (day 4 to day 21), and remodeling stage including the reassembling of the extracellular matrix and the collagen fibers (day 14 and day 21) were observed in histological analysis after the tissue welding operation.

on/200 ms off, for a total "on" duration of 5 s). Each laser dose was sampled by two rats (with 12 incisions) for first, fourth, seventh, fourteenth, and twenty-first postoperative days, and then tensile strength analysis was performed. The skin samples were strained perpendicularly to the axis of the closure until breakage failure and tensile break values were recorded.

At day 1, the tensile force (TF) values were found as $4.78 \pm 1.54 \mathrm{~N}$ for the $\mathrm{CW}$ mode of operation and $4.67 \pm 1.75 \mathrm{~N}$ for the modulated mode of operation. TF values found at day 4 were $5.17 \pm 0.93 \mathrm{~N}$ and $5.21 \pm 0.66 \mathrm{~N}$ for $\mathrm{CW}$ and modulated modes of operation, respectively. At day 7 , the TF values were found to be $5.57 \pm 2.85 \mathrm{~N}$ for the $\mathrm{CW}$ mode of operation and $5.98 \pm 2.29 \mathrm{~N}$ for the modulated mode of operation. At day 14, the TF values were increasing significantly such that they were $11.41 \pm 2.68 \mathrm{~N}$ for the $\mathrm{CW}$ mode of operation and $11.54 \pm 3.22 \mathrm{~N}$ for the modulated mode of operation. At the last healing period day 21, the TF values were measured as $14.39 \pm 1.59 \mathrm{~N}$ for the $\mathrm{CW}$ mode of operation and 18.66 $\pm 4.84 \mathrm{~N}$ for the modulated mode of operation (Fig. 7). When CW and modulated modes of operation were compared, there was no statistically significant difference between $\mathrm{CW}$ and modulated modes for day 1 ( $p$ $=0.88)$, day $4(p=0.93)$, day $7(p=0.68)$, day $14(p=0.83)$, and day $21(p=0.10)$. There was a statistically significant value between day 7 and day 14 for both CW $(p<0.01)$ and modulated $(p<0.01)$ modes of operation. In addition, TF was found statistically significant among day 14 and day 21 ( $p$ $<0.01$ ) for the modulated mode of operation.

$\mathrm{TF}$ by suture technique was found to be $0 \mathrm{~N}$ for day 1 , $1.64 \pm 0.38 \mathrm{~N}$ for day $4,3.06 \pm 0.65 \mathrm{~N}$ for day 7 , $7.12 \pm 0.99 \mathrm{~N}$ for day 14 , and $9.17 \pm 2.28 \mathrm{~N}$ for day 21 . When the TF values found by Tm:YAP laser welding were compared with the TF values found by suture technique, the TF values found for both modulated and CW modes of operation were significantly higher $(p<0.01)$ than the TF values found for the conventional suture technique. Therefore, 


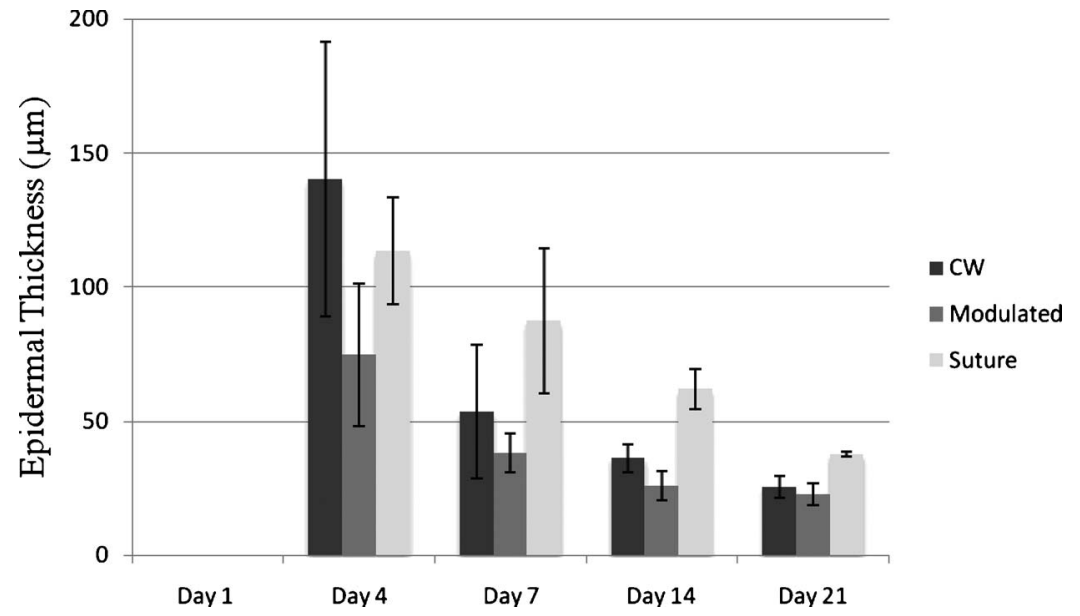

Fig. 5 Epidermal thickness during 21-day healing period. ET values among CW and modulated groups were found statistically significant at day 4 , day 7 , and day 14 . ET values in suture samples were found significantly higher at day 7 , day 14, and day 21 .

Tm:YAP laser welding possessed significantly stronger closure than conventional suture technique. This was another quantitative parameter that showed the success of laser tissue welding by Tm:YAP laser.

\subsection{Discussion}

Determining the optimal laser parameters to minimize the thermal damage and maximize the healing effect associated with laser irradiation is the main concern for clinical application of laser tissue welding. For optimal laser parameters for successful tissue welding, uniform heating of the full thickness of the tissue is desired, and the damage to tissue from excessive laser heating should be prevented. The advantages of laser tissue welding can be achieved by optimum laser wavelength, power density, pulse duration, and spot size. Therefore, an experimental study of dose determination was performed to find the optimal parameters that provide welding with highest success. The determined laser parameters were found as a power of $100 \mathrm{~mW}$, an average light intensity of
$34.66 \mathrm{~W} / \mathrm{cm}^{2}$, and an exposure duration of $5 \mathrm{~s}$ in both $\mathrm{CW}$ and modulated modes of operation. Histological and tensile sampling analysis were performed to prove the success of laser tissue welding by Tm:YAP laser.

By histological analysis of laser-welded incisions, the healing process was observed in four levels: (1) thermal inflammation, (2) granulation formation, (3) tissue remodeling, and (4) extracellular matrix. The healing process is also dependent on the effect of elevated temperature on cell survivability, the thermal stability of the biochemical elements in the acute phase of wound healing, and the endogenous growth factors. ${ }^{25,26}$ Laser tissue welding mechanisms include denaturation of structural proteins, dehydration of the proteins, acceleration of natural fibrinogen polymerization, collagen-tocollagen fusion, cross-linking of proteins, formation of noncovalent bonding between collagen, and interdigitation of collagen fibers. ${ }^{27}$ In addition, temperatures lower than $60^{\circ} \mathrm{C}$ suggested a possible alternative mechanism of photochemical annealing of collagen fibrils. ${ }^{28}$ The most probable mechanism

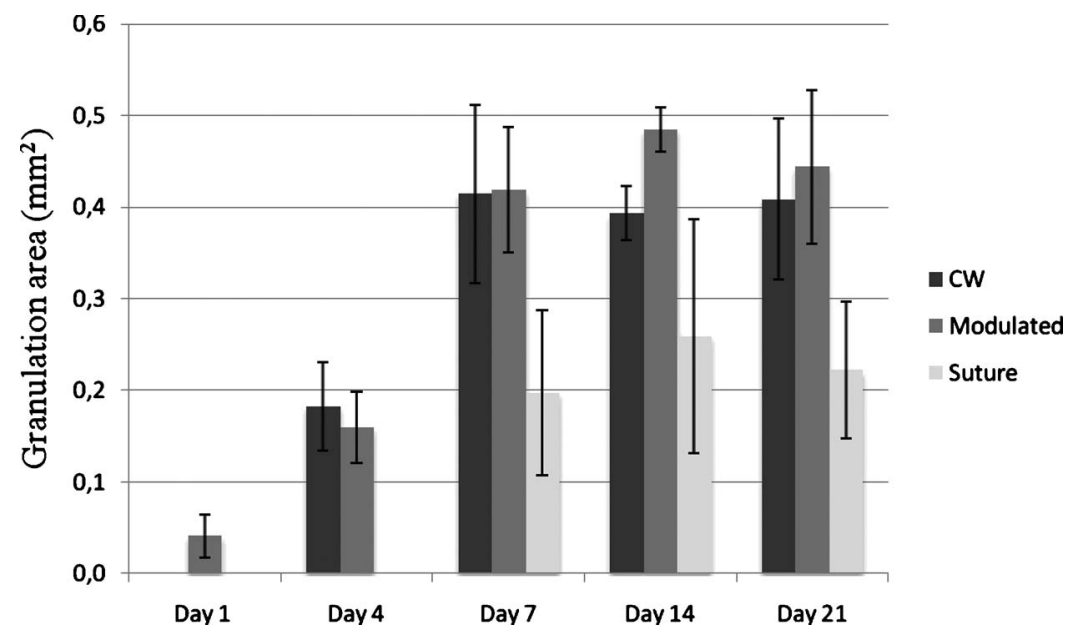

Fig. 6 Granulation area during 21-day healing period. At day 1 and day 14, the GA value was found higher for the samples exposed to the modulated mode of operation. GA values in the suture group were found to be less than both modulated and CW modes of operation ( $p$ $<0.01)$. 


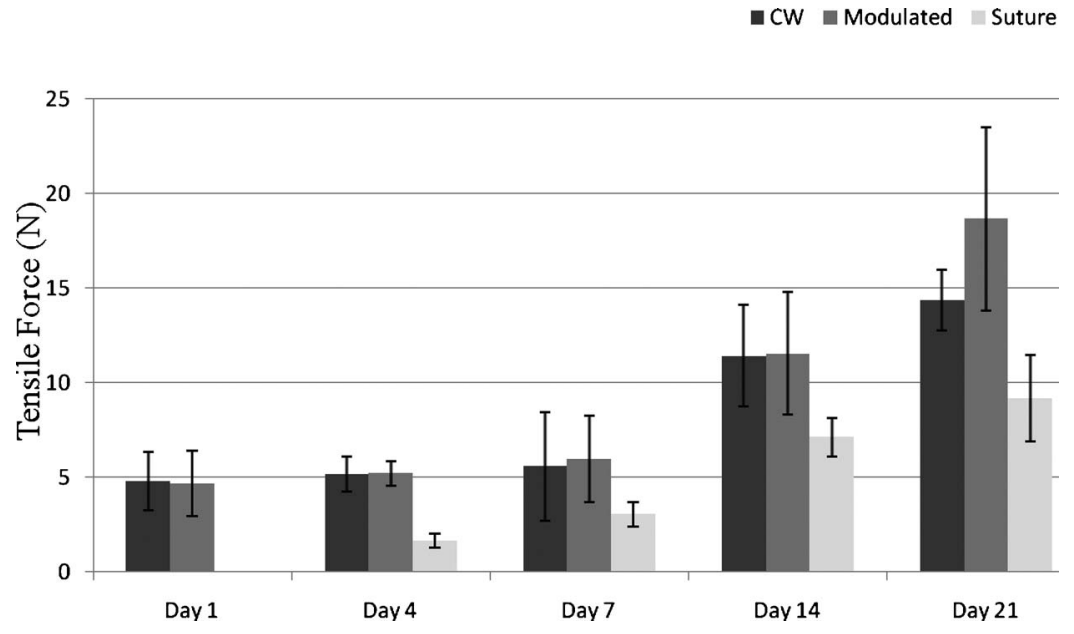

Fig. 7 Tensile forces during 21-day healing period. There was no statistically significant difference between CW and modulated modes for all healing periods. The TF values found for both modulated and CW modes of operation were significantly higher $(p<0.01)$ than the TF values found for the conventional suture technique.

of Tm:YAP laser welding is the thermal coagulation of tissue and heat-induced collagen contracture. The Tm:YAP laser offers minimal thermal damage to the dermis due to the high absorption by water.

Collagen in skin tissues plays a major role in laser tissue welding. Thermal denaturation of the collagen fibers provides tissue welding. ${ }^{29}$ The laser heating induces the fusion of collagen fibers on both sides of the incision. After laser irradiation, the collagen fibrils are swollen, densely packed, and fused together. Cell membranes are disrupted, and the proteins of the cell leak. These proteins undergo a thermal degradation of the bonds and form new molecular bonds due to cooling. There is also an effect of stimulating collagen synthesis after laser welding. When the laser is applied, the heat-labile intramolecular cross-links of collagen are broken, and the collagen undergoes a transition from a highly organized crystalline structure to a random state, which is the denaturation process. When the laser is applied to the tissue, the collagen fibrils are thickened and shrink as a consequence of the unwinding of the triple helix. ${ }^{30}$ As the structural basis for the laser tissue welding, the unwinding of the triple helix follows interdigitation during the cooling and healing period. ${ }^{2}$ The effects of heating on collagen can be reversible or irreversible, depending on the collagen content, the maximum temperature reached, the exposure time, and the mechanical stress applied to the tissue during heating. ${ }^{31}$ Excessive temperature increase in collagens forms a subsequent loss of fibrillar integrity.

By histology analysis, the low power levels of the Tm:YAP laser at $100 \mathrm{~mW}$ and $5 \mathrm{~s}$ duration for both $\mathrm{CW}$ and modulated modes of operation were found successful for tissue welding applications in Wistar rat skin with minimal thermal damage and strong welds compared to the suture technique. CI values by laser-welded incisions were found higher than the suture samples at day 1. Furthermore, CI values were found to be 1 at day 4 for laser-welded samples, whereas suture samples were not closed at day 4. On the other hand, ET was found lower for modulated application than $\mathrm{CW}$ mode application of the Tm:YAP laser system. However, TAA was not statistically significant among $\mathrm{CW}$ and modulated modes of operation.
The histological parameters found in this study were compared with the results found in a comparison study performed by the same methodology with 809 -nm diode laser $(0.5 \mathrm{~W}$, $5 \mathrm{~s}$ ) with solder ( $25 \%$ bovine serum albumin), 910-nm diode laser $(0.5 \mathrm{~W}, 5 \mathrm{~s})$, and $1070-\mathrm{nm}$ ytterbium fiber laser $(0.5 \mathrm{~W}$, $5 \mathrm{~s}$ ), where the 1070-nm fiber laser yielded noticeably stronger bonds than the near-infrared laser. ${ }^{32} \mathrm{CI}$ was significantly higher by the Tm:YAP laser $(0.1 \mathrm{~W}, 5 \mathrm{~s})$ than the ytterbium fiber laser at day $4(\mathrm{CI}=0.24 \pm 0.29$ at day 4 for $1070-\mathrm{nm}$ fiber laser). TAA was not observed by Tm:YAP laser application, whereas the ytterbium fiber laser formed TAA of $0.05 \pm 0.01 \mathrm{~mm}^{2}$. The TAA values among the Tm:YAP laser and the ytterbium fiber laser were not found statistically significant at day 1 . ET values were found higher by Tm:YAP laser at day 4 , and they are not statistically significant after day 4.

Due to the higher water absorption near $1980 \mathrm{~nm}$, lower power levels of Tm:YAP lasers (compared to lower wavelength lasers) are found sufficient for tissue welding, and no solder is necessary to increase the absorption effect. This decreases the operation time and adverse effects due to the solders. The solder, acting as a biological glue, absorbs laser energy to increase the effect of denaturation and coagulation of protein components to bond tissue incisions. Three disadvantages of the solid protein solders have been reported: ${ }^{33}$

1. Most of the energy is generally absorbed near the upper portion of the solder.

2. The protein solder is soluble in physiological solutions. They can be mixed by blood dilution, and this mechanical alteration can weaken tissue welding repair.

3. Protein solders are brittle and inflexible; therefore, they are not easily adapted to various tissue geometries.

In addition, because they are low-viscosity materials, application of fluid solders to the repair site is difficult. Furthermore, solders may have an associated immunological risk. ${ }^{34}$

Unlike the Er:YAG and $\mathrm{CO}_{2}$ lasers, lasers operating at wavelengths shorter than $2.5 \mu \mathrm{m}$ are more desirable for clinical use because their outputs can be transmitted via conven- 
tional, readily available silica fibers. ${ }^{21}$ Furthermore, thermal injury of surrounding tissues can be minimized by using pulsed radiation due to the cooling of the tissue between pulses. ${ }^{35}$ When the laser pulse width is less than the tissue thermal relaxation time, thermal diffusion outside the application area is reduced, and the thermal injury of the surrounding tissues is minimized. ${ }^{36}$

Previous studies found a strong correlation between laser wavelength and the tensile strength of welded tissues. In particular, laser tissue welding at wavelengths with higher water absorption was shown to provide greater tensile strength. Among varying laser wavelengths between $1220 \mathrm{~nm}$ and $1430 \mathrm{~nm}$, the highest tensile strength was achieved at $1430 \mathrm{~nm}$, whose water absorption is the highest. The tensile forces found by Tm:YAP laser were significantly found higher than ytterbium fiber laser after day $1 .{ }^{32}$ At day 1 , the tensile forces were not found statistically significant. The greater water absorption is correlated with the higher tensile strength. ${ }^{37}$ The strong closure by Tm:YAP laser welding was also quantitatively proved by tensile strength analysis. The tensile forces found for both $\mathrm{CW}$ and modulated modes of operation are significantly higher than the values found for the conventional suture technique. Therefore, the Tm:YAP laser at $1980 \mathrm{~nm}$ has proven to possess stronger welds than the closure by suture technique.

In the present study, the tissue welding potential of an infrared laser with high water absorption property was investigated by quantification of closure, thermal damage given, and mechanical strength of welds. CW and modulated modes of operations were comparatively applied. Modulated laser delivery was expected to cause less thermal damage, permitting thermal relaxation of the target tissue. In future, temperature changes of tissue and heat deposition as a function of laser delivery mode can be studied in order to improve the welding quality. New wavelengths of laser with well-defined energy delivery modes may generate enthusiasm for clinical adoption of laser welding.

In conclusion, the Tm:YAP laser system stands as a potentially important candidate for tissue welding applications with accelerated, improved, and strong healing. Further studies are clearly worthwhile to evaluate its full potential for clinical use.

\section{Acknowledgments}

This work was supported by the Scientific and Technological Research Council of Turkey under TUBITAK-107E119 grant to M. Gulsoy, PhD. The authors thank Resit Canbeyli, PhD, for providing the environment to perform in vivo experiments in the Psychobiology Laboratory, Bogazici University. A. Sennaroglu further acknowledges research support provided by the Turkish Academy of Sciences.

\section{References}

1. K. K. Jain and W. Gorisch, "Repair of small blood vessels with the neodymium:YAG laser," Surgery 85, 684-688 (1979).

2. R. Schober, F. Ulrich, T. Sander, H. Dürselen, and S. Hessel, "Laserinduced alteration of collagen substructure allows microsurgical tissue welding," Science 232, 1421-1422 (1986).

3. I. Cilesiz, S. Thomsen, A. J. Welch, and E. K. Chan, "Controlled temperature tissue fusion: Ho:YAG laser welding of rat intestine in vivo, part two," Lasers Surg. Med. 21, 278-286 (1997).

4. F. Rossi and R. Pini, "Experimental and model analysis on the tem- perature dynamics during diode laser welding of the cornea," $J$. Biomed. Opt. 12, 14-31 (2007).

5. I. C. Wolf-deJonge, M. Heger, J. van Marle, R. Balm, and J. F. Beek, "Suture-free laser-assisted vessel repair using $\mathrm{CO}_{2}$ laser and liquid albumin solder," J. Biomed. Opt. 13, 32-44 (2008).

6. E. K. Chan, Q. Lu, B. Bell, M. Motamedi, C. Frederickson, D. T. Brown, I. S. Kovach, and A. J. Welch, "Laser assisted soldering: microdroplet accumulation with a microjet device," Lasers Surg. Med. 23, 213-220 (1998).

7. A. Lauto, "Repair strength dependence on solder protein concentration: a study in laser tissue-welding," Lasers Surg. Med. 22, 120-125 (1998).

8. J. M. Massicotte, R. B. Stewart, and D. P. Poppas, "Effects of endogenous absorption in human albumin solder for acute laser wound closure," Lasers Surg. Med. 23, 18-24 (1998).

9. B. Lobel, O. Eyal, N. Kariv, and A. Katzir, "Temperature controlled $\mathrm{CO}_{2}$ laser welding of soft tissues: urinary bladder welding in different animal models (rats, rabbits, and cats)," Lasers Surg. Med. 26, 4-12 (2000).

10. Y. Kamegaya, W. A. Farinelli, A. V. V. Echague, H. Akita, J. Gallagher, T. J. Flotte, R. R. Anderson, R. W. Redmond, and I. E. Kochevar, "Evaluation of photochemical tissue bonding for closure of skin incisions and excisions," Lasers Surg. Med. 37, 264-270 (2005)

11. D. Simhon, T. Brosh, M. Halpern, A. Ravid, T. Vasilyev, N. Kariv, A. Katzir, and Z. Nevo, "Closure of skin incisions in rabbits by laser soldering. I: Wound healing pattern," Lasers Surg. Med. 35, 1-11 (2004).

12. D. Simhon, M. Halpern, T. Brosh, T. Vasilyev, A. Ravid, T. Tennenbaum, Z. Nevo, and A. Katzir, "Immediate tight sealing of skin incisions using an innovative temperature-controlled laser soldering device in in vivo study in porcine skin," Ann. Surg. 245, 206-213 (2007).

13. D. D. M. Ho, R. London, G. B. Zimmerman, and D. A. Young, "Laser-tattoo removal-a study of the mechanism and the optimal treatment strategy via computer simulations," Lasers Surg. Med. 30 389-397 (2002).

14. M. C. Oz, L. S. Bass, H. W. Popp, R. S. Chuck, J. P. Johnson, S. L. Trokel, and M. R. Treat, "In vitro comparison of thulium-holmiumchromium:YAG and argon ion lasers for welding of biliary tissue," Lasers Surg. Med. 9, 248-253 (2005).

15. H. W. Popp, M. C. Oz, L. S. Bass, R. S. Chuck, S. L. Trokel, and M. R. Treat, "Welding of gallbladder tissue with a pulsed $2.15 \mu \mathrm{m}$ thulium-holmium-chromium:YAG laser," Lasers Surg. Med. 9, 155159 (2005).

16. A. K. Ngo, U. Sharma, J. U. Kang, and N. M. Fried, "Laser welding of urinary tissues, ex vivo, using a tunable thulium fiber laser," Proc. SPIE 6078, 1-8 (2006).

17. B. Ott, B. J. Züger, D. Erni, A. Banic, T. Schaffner, H. P. Weber, and M. Frenz, "Comparative in vitro study of tissue welding using a $808 \mathrm{~nm}$ diode laser and a Ho:YAG laser," Lasers Med. Sci. 16, 260266 (2001).

18. R. B. Stewart, A. Benbrahim, G. M. LaMuraglia, M. Rosenberg, G. J. L'ltalien, W. M. Abbott, and R. T. V. Kung, "Laser assisted vascular welding with real time temperature control," Lasers Surg. Med. 19, 9-16 (1996).

19. G. M. Hale and M. R. Querry, "Optical constants of water in the $200 \mathrm{~nm}$ to $200 \mu \mathrm{m}$ wavelength region," Appl. Opt. 12, 555-563 (1973).

20. D. M. Wieliczka, S. Weng, and M. R. Querry, "Wedge shaped cell for highly absorbent liquids: infrared optical constants of water," Appl. Opt. 28, 1714-1719 (1989).

21. A. F. El-Sherif and T. A. King, "Soft and hard tissue ablation with short-pulse high peak power and continuous thulium-silica fiber lasers," Lasers Med. Sci. 18, 139-147 (2003).

22. B. Chen, S. L. Thomsen, R. J. Thomas, J. Oliver, and A. J. Welch, "Histological and modeling study of skin thermal injury to $2.0 \mu \mathrm{m}$ laser irradiation," Lasers Surg. Med. 40, 358-370 (2008).

23. H. Kalaycioglu, A. Sennaroglu, and A. Kurt, "Influence of doping concentration on the power performance of diode-pumped continuous-wave $\mathrm{Tm}^{3+}: \mathrm{YAlO}_{3}$ lasers," IEEE J. Sel. Top. Quantum Electron. 11, 667-673 (2005).

24. M. Gulsoy, Z. Dereli, and H. O. Tabakoglu, "Closure of skin incisions by 980-nm diode laser welding," Lasers Surg. Med. 21, 5-10 (2006).

25. D. P. Poppas, R. B. Stewart, J. M. Massicotte, A. E. Wolga, R. T. V 
Kung, A. B. Retik, and M. R. Freeman, "Temperature-controlled laser photocoagulation of soft tissue: in vivo evaluation using a tissue welding model," Lasers Surg. Med. 18, 335-344 (1996).

26. W. T. Lawrence, "Physiology of the acute wound," Clin. Plast. Surg. 25, 321-340 (1998).

27. T. Menovsky, J. F. Beek, and M. J. C. van Gemert, "Laser tissue welding of dura mater and peripheral nerves: a scanning electron microscopy study," Lasers Surg. Med. 19, 152-158 (1996).

28. G. E. Kopchok, R. A. White, G. H. White, R. Fujitani, J. Vlasak, L. Dykhovsky, and W. S. Grundfest, " $\mathrm{CO}_{2}$ and argon laser vascular welding: acute histologic and thermodynamic comparison," Lasers Surg. Med. 8, 584-588 (1988).

29. G. S. Abela, E. E. Hage-Korban, T. Tomaru, G. R. Barbeau, O. G. Abela, and S. E. Fried, "Vascular procedures that thermo-coagulate collagen reduce local platelet deposition and thrombus formation: laser and laser-thermal versus balloon angioplasty," Lasers Surg. Med. 29, 455-463 (2001).

30. J. C. Allain, M. LeLous, L. Cohen-Solal, S. Bazin, and P. Maroteaus, "Isometric tensions developed during the hydrothermal swelling of rat skin," Connect. Tissue Res. 7, 127-133 (1980).
31. F. Xu, T. J. Lu, and K. A. Seffen, "Biothermomechanical behavior of skin tissue," Acta Mech. Sin. 24, 1-23 (2008).

32. H. Ö. Tabakoğlu and M. Gülsoy, "In vivo comparison of near infrared lasers for skin welding," Lasers Surg. Med. 25, 411-421 (2009).

33. K. M. McNally, B. S. Sorg, and A. J. Welch, "Novel solid protein solder designs for laser-assisted tissue repair," Lasers Surg. Med. 27, 147-157 (2000).

34. R. B. Stewart, C. B. Bleustein, P. B. Petratos, K. C. Chin, D. P. Poppas, and R. T. V. Kung, "Concentrated autologous plasma protein: a biochemically neutral solder for tissue welding," Lasers Surg. Med. 29, 336-342 (2001).

35. A. V. McDonald, N. M. Claffey, G. J. Pearson, W. Blau, and D. J. Setchell, "Effect of Nd:YAG radiation at millisecond pulse duration on dentine crater depth," Lasers Surg. Med. 27, 213-223 (2000).

36. A. M. Karamzadeh, B. J. F Wong, R. L. Crumley, and G. Ahuja, "Lasers in pediatric airway surgery: current and future clinical applications," Lasers Surg. Med. 35, 128-134 (2004).

37. J. Tang, J. M. Evans, V. Petricevic, P. Ho, and P. R. Alfano, "Tissue welding using near-infrared forsterite and cunyite tunable lasers," IEEE J. Sel. Top. Quantum Electron. 5, 1103-1106 (1999). 